\title{
PERCEPÇÃO DO RISCO BIOLÓGICO EM TRABALHADORES DE ENFERMAGEM*
}

Leticia Gramazio Soares², Leila Maria Mansano Sarquis², Ana Lúcia Cardoso Kirchhof ${ }^{3}$, Elaine Drehmer de Almeida Cruz ${ }^{2}$

RESUMO: Esta pesquisa descritiva exploratória de abordagem qualitativa teve por objetivo identificar a percepção dos trabalhadores sobre risco biológico em sua prática profissional e foi realizada de janeiro de 2008 a janeiro de 2009 em um município do interior do Paraná. A coleta de dados foi realizada por meio de entrevista semiestruturada, gravada e transcrita a 18 trabalhadores da enfermagem, observando-se o critério de saturação de dados. A análise se deu pelo agrupamento de semelhanças e diferenças apresentadas nas falas temáticas e da qual revelou-se três temas centrais: percepção sobre risco biológico; preparo técnico profissional e apoio institucional e condições de trabalho, os quais deram origem à seis categorias. Concluiu-se que os trabalhadores reconhecem o risco, contudo desconsideram a possibilidade de sofrer um acidente, o que contribui para baixa adesão à medidas preventivas; desejam ser supervisionados em suas atividades e apontam aspectos administrativos como contribuintes à não adesão à medidas preventivas.

DESCRITORES: Saúde do trabalhador; Acidentes e eventos biológicos; Enfermagem; Riscos ocupacionais; Pessoal de saúde.

\section{PERCEPTION OF BIOLOGICAL RISK AMONG NURSING WORKERS}

ABSTRACT: This descriptive, exploratory research with a qualitative approach aimed to identify the workers' perception of biological risks in their professional practice, and was carried out between January 2008 and January 2009 in a municipality in the State of Paraná. Data collection was achieved through semi-structured interviews, recorded and transcribed, held with 18 nursing workers, observing the criteria of data saturation. Analysis was undertaken by the grouping of similarities and differences presented in the thematic accounts and which revealed three central themes: perceptions about biological risks; technical professional preparation and institutional support and work conditions, which gave rise to six categories. It was concluded that although the workers recognize the risk, nevertheless they do not take into account the possibility of suffering an accident, which contributes to the poor compliance with preventive measures; they desire to be supervised in their activities and indicate administrative aspects as contributing to the failure to comply with preventive measures.

DESCRIPTORS: Worker's health; Biological accidents and events; Nursing; Occupational risks.

\section{PERCEPCIÓN DEL RIESGO BIOLÓGICO EN TRABAJADORES DE ENFERMERÍA}

RESUMEN: Esta investigación descriptiva exploratoria de abordaje cualitativo tuvo el objetivo de identificar la percepción de los trabajadores sobre riesgo biológico en su práctica profesional y fue realizada de enero de 2008 a enero de 2009 en municipio del interior de Paraná. Los datos fueron recogidos por medio de entrevista semiestructurada, grabada y transcrita, a 18 trabajadores de enfermería, observándose el criterio de saturación de datos. El análisis fue hecho por agrupamiento de semejanzas y diferencias presentadas en las hablas temáticas y de la cual resultaron tres temas centrales: percepción acerca del riesgo biológico; preparación técnica profesional y apoyo institucional y condiciones de trabajo, los cuales resultaron en seis categorías. Se concluyó que los trabajadores reconocen el riesgo, sin embargo desconsideran la posibilidad de sufrir un accidente, lo que contribuye para la pequeña adhesión a las medidas preventivas; desean ser supervisionados en sus actividades y apuntan aspectos administrativos como contribuyentes a la no adhesión a las medidas preventivas. DESCRIPTORES: Salud del trabajador; Accidentes y eventos biológicos; Enfermería; Riesgos ocupacionales.

*Extraído da dissertação 'O risco biológico entre trabalhadores de enfermagem: uma realidade a ser compreendida' apresentada ao Programa de Pós-Graduação em Enfermagem da Universidade Federal do Paraná em 2010.

'Enfermeira. Mestre em Enfermagem. Professora da Faculdade Guairacá e de Universidade Estadual do Centro-Oeste.

${ }^{2}$ Enfermeira. Doutora em Enfermagem. Professora do Departamento e do Programa de Pós-Graduação de Enfermagem da Universidade Federal do Paraná - PPGENF UFPR. Membro do Grupo de Pesquisa Multiprofissional em Saúde do Adulto - GEMSA.

${ }^{3}$ Enfermeira. Doutora em Enfermagem. Pesquisadora visitante do PPGENF UFPR.

Autor correspondente:

Leila Maria Mansano Sarquis

Universidade Federal do Paraná

R. Pref. Lothário Meissner, 632 - 80210-170 -Curitiba-PR-Brasil

E-mail: leilammsarquis@gmail.com
Recebido: 16/07/2012 Aprovado: 29/11/2012

Cogitare Enferm. 2013 Jan/Mar; 18(1):36-42 


\section{INTRODUÇÃO}

Os trabalhadores de enfermagem são considerados profissionais de alto risco para sofrer acidentes de trabalho com exposição a material biológico. Esta situação relaciona-se ao cuidado direto que esses prestam aos pacientes e, também, devido à diversidade e à frequência dos procedimentos realizados no cotidiano assistencial, o que os expõe ao risco de contato com microrganismos patogênicos presentes no sangue e fluidos orgânicos ${ }^{(1-2)}$. Essa problemática se potencializa nas instituições hospitalares, local que emprega grande número de profissionais de enfermagem e onde o cuidado direto é exercido a pessoas doentes, muitas das quais portadoras de patologias potencialmente transmissíveis.

A exposição ocupacional a material biológico é entendida como a possibilidade de contato com sangue e fluidos orgânicos no ambiente de trabalho. Entre as formas de exposição incluem-se a inoculação percutânea, por intermédio de agulhas ou objetos cortantes e o contato direto com pele e/ou mucosas ${ }^{(3)}$. As doenças potencialmente transmissíveis, como Aids (Síndrome da Imunodeficiência Humana) e Hepatites B e C representam risco à Saúde do Trabalhador da Área da Saúde ${ }^{(4-5)}$.

Considerando as características do trabalho e o quantitativo de profissionais da categoria, o risco biológico em trabalhadores da enfermagem tem sido foco de preocupação de pesquisadores ${ }^{(2,4-6)}$. Neste contexto, ações direcionadas ao ambiente no qual a atividade profissional é desempenhada tem papel fundamental na prevenção de acidentes e doenças relacionadas ao trabalho. Porém, pouca importância tem sido atribuída ao trabalhador em si, o que reflete na exposição aos riscos.

O cotidiano assistencial em ambiente insalubre, ou de riscos, pode contribuir para a diminuição da percepção dos trabalhadores sobre a necessidade de adotar medidas preventivas para a sua própria segurança ${ }^{(7)}$. Neste sentido, é indispensável a formação de consciência individual, coletiva e permanente, pela equipe de enfermagem, sobre os riscos ocupacionais aos quais se expõe na prática profissional.

A adoção de medidas contínuas de biossegurança no ambiente de trabalho é imprescindível para a prevenção de acidente e doenças ocupacionais, sendo recomendado e preconizado pela legislação o uso de equipamentos de proteção individual (EPI), bem como a correta manipulação e supervisão para o seu uso ${ }^{(3)}$.

A exposição ao risco biológico é favorecida na prática da enfermagem por fatores relativos ao pró- prio processo de trabalho, e não somente pela falta de percepção ou consciência do risco. São fatores contribuintes à ocorrência de acidentes a longa jornada de trabalho, o número reduzido de funcionários, a redução da atenção, o ritmo de trabalho acelerado, a assistência contínua, o contato direto com o paciente, a diversidade de patologias entre os assistidos e a constante manipulação e o descarte de materiais perfurocortantes ${ }^{(2,8)}$.

Sobre o conhecimento de normas de biossegurança, estudos tem mostrado que os trabalhadores avaliam o procedimento e julgam a necessidade, ou não, de utilizar EPI, não valorizando, muitas vezes, a real importância do seu uso para a prevenção de acidentes. Os profissionais, em sua maioria, conhecem as medidas de biossegurança, mas não se posicionam adequadamente, e nem sempre seguem as precauções padrão, resultando em alto índice de acidentes de trabalho com exposição a material biológico ${ }^{(4-6)}$.

As dificuldades de aceitação e cumprimento de medidas preventivas são fatores existentes e, por isso, preocupantes. Mas, se o risco biológico está presente na prática diária da enfermagem, a utilização de tais medidas pelos trabalhadores não pode ser ignorada, e sim esclarecida e discutida, no sentido de maximizar estratégias de prevenção à exposição. Deste modo, a saúde do trabalhador de enfermagem tem despertado preocupação, pois quanto maior o esclarecimento sobre o risco, bem como a adoção de medidas de biossegurança, menor a possibilidade da ocorrência de doenças relacionadas ao trabalho adquiridas por meio da exposição a material biológico.

Entender a percepção sobre risco biológico que os trabalhadores de enfermagem possuem é importante, pois pode direcionar ações que promovam o comportamento seguro. Neste sentido, o objetivo deste estudo foi identificar a percepção dos trabalhadores de enfermagem sobre risco biológico na sua prática profissional.

\section{MÉTODO}

Trata-se de uma pesquisa descritiva exploratória de abordagem qualitativa, realizada no período de janeiro de 2008 a janeiro de 2009 em um hospital de um município do interior do Paraná, com trabalhadores de enfermagem da Clínica Médico-Cirúrgica, cujo serviço era composto por 39 trabalhadores, entre enfermeiros, técnicos e auxiliares de enfermagem.

Utilizaram-se como critérios de inclusão: ser enfermeiro, auxiliar ou técnico em enfermagem, atuante e pertencente ao quadro de trabalhadores do Serviço 
de Enfermagem da Clínica Médico-Cirúrgica. Foram excluídos os trabalhadores que estavam em período de férias, tratamento de saúde ou licença maternidade no período de coleta dos dados.

Para a coleta de dados foi aplicada entrevista semiestruturada, tendo como questão norteadora "como você percebe o risco biológico na sua prática profissional?" A entrevista foi gravada e posteriormente transcrita na íntegra, com o objetivo de identificar a percepção sobre o risco biológico entre os trabalhadores. Os dados foram analisados pelo agrupamento de semelhanças e diferenças apresentadas nas falas temáticas que possibilitam construir categorias, agrupando elementos, ideias ou expressões em torno de um conceito abrangente dessas dimensões ${ }^{(9)}$. A participação de 18 trabalhadores de enfermagem foi suficiente por ser possível verificar a saturação dos dados, que se tornaram repetitivos entre os participantes, o que foi satisfatório para alcançar o objetivo da pesquisa.

Esta pesquisa está regulamentada pela Resolução n. 196/96 e passou por aprovação do Comitê de Ética em Pesquisa da Universidade Federal do Paraná, conforme registro CEP/SD 841.176.09.11 e CAAE 4570.0.000.091-09. Os participantes ao aceitarem participar da pesquisa, assinaram o Termo de Consentimento Livre e Esclarecido.

\section{RESULTADOS}

A análise qualitativa das respostas dos articipantes da pesquisa permitiu observar a ocorrência de três temas centrais, que deram origem a seis categorias (Quadro 1).

Quadro 1- Temas e categorias relacionadas à percepção dos trabalhadores de enfermagem sobre risco biológico. Paraná, 2010

\begin{tabular}{|l|l|}
\hline \multicolumn{1}{|c|}{ TEMAS } & \multicolumn{1}{c|}{ CATEGORIAS } \\
\hline \multirow{2}{*}{$\begin{array}{l}\text { 1. Percepção sobre } \\
\text { risco biológico }\end{array}$} & $\begin{array}{l}\text { Prepeparo técnico profissional e } \\
\text { apoio institucional }\end{array}$ \\
\cline { 2 - 2 } & Condições de trabalho \\
\hline $\begin{array}{l}\text { 2. Preparo técnico } \\
\text { profissional e apoio } \\
\text { institucional }\end{array}$ & $\begin{array}{l}\text { Preparo técnico profissional e } \\
\text { apoio institucional }\end{array}$ \\
\cline { 2 - 2 } $\begin{array}{l}\text { Organização institucional } \\
\text { visando a prevenção }\end{array}$ \\
\hline trabalho Condic̃es de & $\begin{array}{l}\text { Características do trabalho } \\
\text { que aumentam a exposição } \\
\text { ao risco }\end{array}$ \\
\hline
\end{tabular}

\section{Percepção sobre risco biológico}

Nesta categoria os trabalhadores de enfermagem referiram perceber o risco biológico como inerente à sua prática profissional e presente nas atividades cotidianas. Os profissionais reconhecem o risco e entendem que a consciência de cada trabalhador é fator determinante para a prevenção. Estes fatos podem ilustrados pelas seguintes falas:

[o risco biológico] é uma característica da profissão, um detalhe que tem e sempre vai ter [...]. Quem está na área tem que saber desse risco para poder evitar. Sempre está presente, a gente não vê os microrganismos, mas temos que levar isso com a gente para poder evitar o contato [...]. (Entrevistado 5)

Tem risco, mas fica na escolha de cada um se prevenir, ou não [...]. (Entrevistado 3)

É o risco de pegar uma doença pelo sangue de pacientes, que pode estar contaminado. (Entrevistado 13)

Embora percebam o risco biológico na sua prática, os trabalhadores demonstram certa descrença ao real risco, e faça parte do cotidiano, os trabalhadores lhe atribuem pouca importância, revelando comportamentos que propiciam maior exposição. Tal constatação pode ser verificada nas falas seguintes:

Todo mundo sabe que tem que usar EPI, ninguém vai te dizer: eu não sabia que tinha que usar [o EPI] vai da consciência de cada um em fazer o certo ou não, todo mundo sabe. (Entrevistado 3)

Sempre existe o perigo de ficar doente, de pegar doenças, infecções e até de ficar estressada e depressiva por conta do trabalho, mas eu não ligo [...]. (Entrevistado 6)

Tem que ter um limite, pensar na gente e no paciente, mas o que não dá é ficar só pensando em acidente, em EPI, com preocupação em pegar doença e tal. É muito dificil disso acontecer, na minha opinião. (Entrevistado 18)

Ao desconsiderar o risco, os trabalhadores de enfermagem expressam sentimentos como medo, ansiedade e valorização da espiritualidade para enfrentar a vivência diária à exposição. Abaixo, algumas das falas que revelam esta categoria: 
Eu sinto medo, porque posso pegar uma doença, até aids [...]. (Entrevistado 1)

Eu entrego todos os dias meu trabalho nas mãos de Deus, Ele cuida de mim, me protege em tudo [...] uso sim [EPI] eu também faço a minha parte, mas entrego tudo a Ele. (Entrevistado 4)

Eu confio em Deus, ele me guia [...]. (Entrevistado 15)

\section{Preparo técnico profissional e apoio institucional}

Frente à relação entre teoria e prática na prevenção, os trabalhadores ao falarem sobre risco biológico, salientam a importância do conhecimento adquirido nos cursos de formação e em atividades de capacitação. Observou-se que os trabalhadores possuem conhecimento teórico sobre o tema, porém a prática ou os hábitos de comportamento de risco suplantam a prática adequada e preventiva. Apresenta-se abaixo as principais falas que deram origem ao tema:

[o risco] é uma coisa que a gente já sabe, já aprendemos bem isso no curso e nas capacitações. (Entrevistado 17)

A gente até sabe, mas não faz tudo como tem que ser. Acaba vacilando muitas vezes, não por não saber, mas porque, sei lá, não é muito fácil fazer tudo certo [...] porque já virou hábito, prá mim pelo menos. Não vou te mentir, mas faço muita coisa sem usar EPI. (Entrevistado 1)

Todos sabemos, todos mesmo, mas sabe como é, na hora de colocar em prática ninguém, ou quase ninguém, usa o que aprendeu [...]. (Entrevistado 8)

A categoria organização institucional visando a prevenção os trabalhadores percebem que a prevenção ao risco biológico também está atrelada a aspectos organizacionais da instituição hospitalar, ressaltando o valor atribuído as atividades de supervisão e educação em saúde. As falas abaixo demonstram a categoria:

Já percebi que falam, falam, falam [...] se talvez tivesse supervisão, numa boa, não para brigar [...] seria um incentivo para a gente utilizar EPI Conversando, com bons exemplos, eu acho legal quando vejo alguém que faz tudo dentro das normas. (Entrevistado 10)

Se houvesse estímulo através dos supervisores [...] supervisionar o nosso trabalho, para o nosso bem, mas não tem. (Entrevistado 4)

Sempre tem palestra, capacitação. Eu participo e acho importante! (Entrevistado 9)

[risco biológico] é um assunto que sempre estão falando, a CCIH, os estagiários, sempre tem capacitação para nós [...]. (Entrevistado 10)

\section{Condições de trabalho}

$\mathrm{Na}$ categoria características do trabalho que aumentam a exposição ao risco verifica-se que os trabalhadores ao abordar o risco biológico, o relacionam às condições de trabalho. Essas condições, sobretudo a sobrecarga de trabalho, quando não adequadas, são referidas como um agravante ao risco de exposição:

Estamos tão cansadas, falta gente para trabalhar, o trabalho acumula, sobra tudo para nós. [...] estamos trabalhando muito! (Entrevistado 6)

Nessa correria, você acha que dá tempo de pôr luvas? $E$, se esquecer, não dá para voltar, perde tempo. É assim nosso trabalho, corrido o tempo todo, nem dá tempo de pensar. (Entrevistado 5)

Eu sei que tenho que usar tudo aquilo, ter atenção, calma e tudo mais, só que também penso no plantão que tenho que entregar, não posso deixar nada para a tarde [...]. (Entrevistado 16)

\section{DISCUSSÃO}

Os resultados do presente estudo enfatizam que os trabalhadores detêm o conhecimento sobre risco biológico, reconhecem-no na prática diária, porém observa-se certa desvalorização, isso faz com que os profissionais não adotem comportamentos preventivos de forma contínua. Deste modo, verifica-se que a não adoção de medidas de biossegurança está associada a descrença da real vulnerabilidade a qual o trabalhador de enfermagem está exposto; essa se apresenta de forma teórica, mas pouca factível de ocorrer para ele, o trabalhador.

A exposição ao risco biológico é evidenciada ao se considerar serem os trabalhadores de enfermagem os profissionais da área da saúde que mais se expõe ao risco ocupacional, essa vulnerabilidade associa-se à 
natureza majoritariamente manual, das ações de cuidado, o que favorece o contato físico com os pacientes. Outro fato contribuinte é a natureza do trabalho, o qual é realizado em turnos e de forma ininterrupta ${ }^{(8,10-11)}$. Portanto, as próprias características da profissão tem colocado os trabalhadores entre os que mais sofrem acidente de trabalho com material biológico potencialmente contaminado ${ }^{(7,10)}$. Neste contexto, salienta-se a importância de compreender diversos fatores, incluindo a percepção frente ao risco.

Contudo, os participantes dessa pesquisa expressaram sentimento de invulnerabilidade durante a realização de procedimentos técnicos de risco e de confiança nas habilidades técnicas, o que transmite um sentimento de proteção, dispensando a atitude preventiva. As medidas de prevenção exigem que o trabalhador reflita sobre a dimensão do seu trabalho e seus desdobramentos na própria saúde. É necessário, portanto, o desenvolvimento de consciência crítica em relação ao risco biológico e sua prevenção. Esta conscientização deve ser conquistada por todos os trabalhadores, aqueles que não a tem, possivelmente, são aqueles que subestimam o risco e se expõem ainda mais.

Sobre os sentimentos como medo, verifica-se que a atenção se torna redobrada na realização de procedimentos e no uso de EPI ${ }^{(12)}$. Do mesmo modo, o medo de adoecer pela exposição ao risco biológico revela que os trabalhadores, no momento de sua prática, refletem sobre as implicações que a exposição pode trazer à sua saúde, além de reconhecerem-no na prática assistencial. Apesar de que nem toda exposição resulte em acidente e adoecimento, pode-se entender que o medo é um aliado na adoção de medidas preventivas. É como se o medo balizasse o comportamento do trabalhador e o fizesse refletir sobre o risco e, assim, adotar medidas seguras de trabalho; ao passo que a falta de medo corrobora para maior exposição ao risco.

O apego religioso é uma estratégia de enfrentamento após a ocorrência do acidente; ao vivenciar situações difíceis a religião é considerada como mecanismo de apoio $^{(7)}$. Nesta pesquisa o sentimento de proteção espiritual foi enfatizado pelos trabalhadores como elemento importante no contexto do risco de exposição a material biológico.

A dicotomia entre teoria e prática é explicada pela literatura,estudos apontam a falta de adesão às normas de biossegurança e descrédito da possibilidade de contaminação; apesar do reconhecimento de tais indicações, muitos trabalhadores demonstram falta de adesão a essas práticas na sua rotina ${ }^{(6,13)}$. Atividades de educação em saúde que, abordem o risco biológico na prática, configuram estratégia favorável para estimular atitudes de prevenção, mas por si só são insuficientes. Assim, além da educação em saúde para a prevenção do risco, a sensibilização a respeito do problema e o desenvolvimento de um senso, individual e coletivo, de responsabilidade também são fatores importantes ${ }^{(10)}$.

Também é relevante que no desenvolvimento da prática seja verificada a operacionalização do conhecimento adquirido. Ressalta-se a importância da formação dos discentes em relação ao risco biológico; orientações adequadas de práticas da manipulação e descarte de material perfurocortante devem ser valorizadas durante a graduação. Salienta-se que a formação dos profissionais de enfermagem deve enfatizar a prevenção de acidentes e a promoção à saúde do trabalhador $^{(10,14)}$. Porém, somente o conhecimento não contribui para a prevenção e percepção do risco dos acidentes, necessitando também de práticas adequadas de estímulo durante as atividades diárias ${ }^{(15)}$.

Quanto à responsabilidade institucional, percebe-se nas falas que os trabalhadores sabem da existência das normas e rotinas da instituição, e esperam da instituição atitude de supervisão sobre o seu próprio comportamento. A literatura aponta que o envolvimento dos trabalhadores no desenvolvimento de normas, rotinas e programas que visem a mudança de comportamento tem demonstrado resultado positivo. É importante a existência de programas de prevenção, com responsável designado, e de uma comissão que inclua trabalhadores afim de avaliar riscos, compilar dados e fazer recomendações para a prevenção ${ }^{(16)}$.

Sobre organização de normas e rotinas, estas devem ser intensivamente adequadas às políticas institucionais, o que poderá levar à maior adesão de medidas preventivas existentes. Assim como, à incorporação de inovações tecnológicas relacionadas ao agravo, priorizando a promoção da saúde no ambiente de trabalho, uma vez que acidentes de trabalho causam prejuízos à vida do acidentado e à instituição $0^{(17)}$. Por outro lado, a educação em saúde, caracterizada por propostas de mudanças, como a adoção de medidas preventivas de biossegurança no ato de cuidar do cliente, é essencial e pertinente na formação do enfermeiro e demais elementos da equipe de enfermagem ${ }^{(18)}$.

Sobre a supervisão de práticas seguras, o gerenciamento acerca do risco biológico entre os trabalhadores da enfermagem não é dever somente do trabalhador, mas também da instituição que deve estar organizada para tais ações, sendo uma delas a supervisão das normas de biossegurança. Neste aspecto, é importante que a 
instituição forneça condições estruturais, supervisione e assegure o emprego de precauções padrão pelos trabalhadores, bem como o aperfeiçoamento e adaptações para atender as necessidades circunstanciais de cada serviço. Neste estudo percebe-se que os trabalhadores valorizam e participam das atividades de capacitação, mas percebe-se falhas na adoção de medidas de adoção, acompanhamento e supervisão de práticas seguras.

As falhas no gerenciamento de recursos humanos, materiais e a falta de adoção de comportamentos seguros são situações que devem ser contempladas no planejamento dos serviços de saúde, tendo em vista a saúde do trabalhador. Na dinâmica do trabalho, as atividades são realizadas sem reflexão, e sim como uma ação apenas para cumprir procedimentos técnicos ${ }^{(6)}$. A supervisão em enfermagem da exposição ao risco biológico é uma atividade difícil, destacando-se a baixa adesão dos profissionais às medidas de precauções padrão, a resistência em utilizar EPI e o desconhecimento dos riscos de exposição ${ }^{(19)}$.

Também é possível verificar em estudos sobre saúde do trabalhador de enfermagem que as condições de trabalho afetam diretamente a maneira de como o trabalhador percebe e se protege do risco biológico ${ }^{(4,6,16,18)}$. A necessidade de mais um emprego exige do profissional de enfermagem a permanência da maioria dos seus anos produtivos em ambiente insalubre, o que aumenta o tempo de exposição aos riscos ocupacionais ${ }^{(18)}$, além de sobrecarregar o trabalhador.

Alguns fatores impedem os trabalhadores de se cuidar, estando tais fatores relacionados com o tipo de trabalho e a carga horária a ser cumprida, atividades cansativas e estressantes, turnos rotativos, manipulação de substâncias tóxicas e presença de fatores de risco de várias naturezas. Tal situação evidencia fatores que por si só prejudicam a integridade física e psíquica do profissional de enfermagem.

\section{CONCLUSÃO}

Esta pesquisa permitiu identificar a percepção dos trabalhadores de enfermagem de um hospital de médio porte do interior do Paraná sobre risco biológico, esses reconhecem o risco de formas distintas. Concluiu-se que concebem o risco como inerente à profissão e, dessa forma, conhecem medidas preventivas e defendem que essas advêm da consciência individual de cada trabalhador, apesar de algumas vezes, a atitude preventiva não ocorrer.

Apesar disso, a não adoção das medidas preventivas também foi percebida, revelou que o fato de os trabalhadores desconsiderarem a exposição não significa que não o percebam. Mas sim, esses possuem percepção equivocada acerca do risco, o que se verifica na descrença à exposição, por não utilizarem EPI. Portanto, neste caso conclui-se, como importante e prioritário o desenvolvimento de ações voltadas para a sensibilização e para a capacitação do trabalhador à prevenção desta exposição. Os trabalhadores relatam conhecer o risco e suas consequências, porém, ainda não adotam medidas de prevenção frente à exposição.

O estudo ainda salienta a importância à supervisão voltada para a execução de práticas seguras que minimizem o risco de exposição a material biológico e que estabeleçam o cumprimento de normas e rotinas.

Conclui-se ainda que a exposição ao risco biológico não envolve somente a equipe de enfermagem; deve haver discussão com os administradores das instituições, que muitas vezes não têm conhecimento das repercussões destes acidentes, e outros órgãos, como conselhos de classe e sindicatos. Também, o envolvimento de outros orgãos no sentido de melhorar as condições de trabalho a que estão expostos os trabalhadores de enfermagem.

\section{REFERÊNCIAS}

1. Nishide VM, Benatti MCC. Riscos ocupacionais entre trabalhadores de enfermagem de uma Unidade de Terapia Intensiva. Rev Esc Enferm USP. [Internet] 2004;38(4) [acesso em 31 jul 2011]. Disponível: http://www. scielo.br/scielo.php?script $=$ sci_arttext\&pid $=\mathrm{S} 0080$ 62342004000400006\&lng=pt. doi: 10.1590/S008062342004000400006.2004;38(4):406-4.

2. Bálsamo AC, Felli VEA. Estudo sobre os acidentes de trabalho com exposição aos líquidos corporais humanos em trabalhadores da saúde de um hospital universitário. Rev. Latino-Am. Enfermagem. [Internet] 2006;14(3) [acesso em 31 jul 2011]. Disponível: http://www. scielo.br/scielo.php?script $=$ sci_arttext\&pid=S0104$11692006000300007 \& \operatorname{lng}=$ pt. doi: 10.1590/S010411692006000300007.

3. Ministério da Saúde (BR). Secretaria de Atenção à Saúde. Departamento de Ações Programáticas Estratégicas Exposição à Material Biológico. Brasília; 2006.

4. Vieira MO, Padilha MICS. O HIV e o trabalhador de enfermagem frente ao acidente com material pérfurocortante. Rev Esc Enferm USP. [Internet] 2008;42(4) [acesso em 31 jul 2011]. Disponível: http://www. scielo.br/scielo.php?script $=$ sci_arttext\&pid $=\mathrm{S} 0080$ 62342008000400026\&lng=pt. doi: 10.1590/S008062342008000400026 . 
5. Silva MKD, Zeitoune RCG. Riscos ocupacionais em um setor de hemodiálise na perspectiva dos trabalhadores da equipe de enfermagem. Esc Anna Nery. [Internet] 2009;13(2) [acesso em 31 jul 2011]. Disponível: http://www.scielo.br/scielo.php?script=sci_ arttext\&pid=S1414-81452009000200007\&lng=pt. doi: 10.1590/S1414-81452009000200007.

6. Sarquis LMMS, Felli, VEA. Os sentimentos vivenciados após exposição ocupacional entre trabalhadores de saúde: fulcro para repensar o trabalho em instituições de saúde. Rev Bras Enferm [Internet] 2009;62(5) [acesso em 31 jul 2011]. Disponível: http://www. scielo.br/scielo.php?script=sci_arttext\&pid=S003471672009000500008\&lng=pt. doi: 10.1590/S003471672009000500008 .

7. Damasceno AP, Pereira MS, Silva e Souza AC, Tipple AFV, Prado MA. Acidentes ocupacionais com material biológico: a percepção do profissional acidentado. Rev Bras Enferm [Internet] 2006;59(1) [acesso em 31 jul 2011]. Disponível: http://www. scielo.br/scielo.php?script=sci_arttext\&pid=S003471672006000100014\&lng=pt. doi: 10.1590/S003471672006000100014 .

8. Soerensen AA, Moriya TM, Hayashida M, Robazzi MLCC. Acidente com material biológico em profissionais do atendimento pré-hospitalar móvel. Rev enferm UERJ [Internet] 2009;17(2) [acesso em 31 jul 2011]. Disponível: http://www.facenf.uerj.br/v17n2/v17n2a17.pdf

9. Minayo MCS. Pesquisa social: teoria método e criatividade. $16^{\mathrm{a}}$ ed. Petrópolis: Vozes; 2000.

10. Canalli RTC, Moriya TM, Hayashida M. Acidentes com material biológico entre estudantes de enfermagem. Rev enferm UERJ [Internet] 2010;18(2) [acesso em 31 jul 2011]. Disponível: http://www.facenf.uerj.br/v18n2/ v18n2a16.pdf

11. Silva JA, Paula VS, Almeida AJ, Villar LM. Acidentes biológicos entre profissionais de saúde. Esc Anna Nery [Internet] 2009;13(3) [acesso em 31 jul 2011]. Disponível: http://www.scielo.br/scielo.php?script=sci arttext\&pid=S1414-81452009000300008\&lng=pt. doi: 10.1590/S1414-81452009000300008.

12. Thiengo MP, Oliveira DC, Rodrigues BMRD. Repercussões sociais de HIV/Aids entre adolescentes: implicações para os cuidados em enfermagem. Rev Esc Enferm USP. [Internet] 2005;39(1) [acesso em 31 jul 2011]. Disponível: http://www.scielo.br/scielo.php?script=sci arttext\&pid=S0080-62342005000100009\&lng=pt. doi: 10.1590/S0080-62342005000100009.
13. Camargo TB, Lacerda MR, Sarquis LMM. Cuidado de si e acidente com material biológico: Teoria Fundamentada nos Dados. Online braz. j. nurs. [Internet] 2010;9(1) [acesso em 31 jul 2011]. Disponível: http://www.objnursing.uff.br/index.php/nursing/article/ view/j.1676-4285.2010.2797

14. Loureiro LA, Gomes AC, Malaguti SE, Canini SRM da S, Machado AA, Gir E. Adesão de profissionais de enfermagem ao seguimento clínico após exposição ocupacional com material biológico. Rev. Eletr. Enf. [Internet] 2009;11(2) [acesso em 31 jul 2011]. Disponível: http://www.fen.ufg.br/revista/v11/n2/pdf/ v11n2a10.pdf

15. Gonçalves JA. Acidente de trabalho entre a equipe assistencial multiprofissional - uma avaliação da subnotificação [dissertação]. Belo Horizonte: Escola de Enfermagem, Universidade Federal de Minas Gerais. [Internet] 2007 [acesso em 31 jul 2011]. Disponível: http://www.bibliotecadigital.ufmg.br/ dspace/bitstream/1843/GCPA-7CTHKK/1/jacqueline_ de_almeida_gon_alves.pdf

16. Wilburn SQ, Eijjkemans G. Preventing needlestick injuries among healthcare workers: a WHO-ICN collaboration. Int J Occup Environ Health. [Internet] 2004;10(4) [acesso em 31 jul 2011]. Disponível: http:// www.ijoeh.com/index.php/ijoeh/article/view/368

17. Magagnini MAM, Ayres JA. Acidentes com material biológico: a realidade de uma instituição hospitalar do interior paulista. REME: rev. min. enferm. 2009;13(1):123-30.

18. Simão SAF, Souza V, Borges RAA, Soares CRG, Cortes EAC. Fatores associados aos acidentes biológicos entre profissionais de enfermagem. Cogitare enferm. [Internet] 2010;15(1) [acesso em 31 jul 2011]. Disponível: http://ojs.c3sl.ufpr.br/ojs2/index.php/ cogitare/article/view/17177/11312

19. Malaguti SE, Hayashida M, Canini SRMS, Gir E. Enfermeiros com cargo de chefia e medidas preventivas à exposição ocupacional: facilidades e barreiras. Rev Esc Enferm USP. [Internet] 2008;42(3). [acesso em 31 jul 2011]. Disponível: http://www. scielo.br/scielo.php?script $=$ sci_arttext\&pid $=\mathrm{S} 0080$ 62342008000300012\&lng=pt. doi: 10.1590/S008062342008000300012 . 